\title{
Saberes acadêmicos nas etnografias de saberes locais indisciplináveis: etno-matemática e outras etno-x
}

\author{
Marcio D'Olne Campos ${ }^{1}$ \\ Universidade Estadual de Campinas (UNICAMP), \\ Instituto de Filosofia e Ciências Humanas, \\ Departamento de Antropologia, Campinas, SP, Brasil
}

\begin{abstract}
Resumo
O artigo propõe um debate crítico sobre a separação preconceituosa entre os saberes da academia ou ciência instituída e os saberes locais de populações de diferentes culturas e organizações sociais distantes da sociedade envolvente. A partir da etnografia dos saberes o material registrado deve ser analisado, já na academia, por interação interdisciplinar de pesquisadores de diversas áreas disciplinares. No campo algum pesquisador particular focaliza a partir de certos domínios do conhecimento que lhe interessam ao praticar a etnografia sem, no entanto, projetar seu interesse disciplinar no seu interlocutor. Do interesse por tudo que se associe à matemática, por exemplo, só após a volta do campo faria sentido usar como técnica, um método de análise próprio de alguma etno$\mathrm{x}$, onde $\mathrm{x}$ é uma das disciplinas da academia que no entender particular desse autor poderia, por exemplo, ser a matemática.
\end{abstract}

Palavras-chave: Etnografia de saberes, Etnociência, Etnomatemática, Educação fundamental, Antropologia

\section{Academic Knowledge in the Ethnographies of Indisciplinable Local Knowledge: ethno-mathematics and other ethno-x}

\begin{abstract}
The article proposes a critical debate about the prejudiced separation between the knowledge of the academy or instituted science and the local knowledge of populations from different cultures and social organizations far from the surrounding society. From the ethnography of knowledge, the registered field material must be analyzed, already in the academy, by interdisciplinary interaction of researchers from different disciplinary areas. In the field, some private researcher focuses on certain areas of knowledge that interest him when practicing ethnography without, however, projecting his disciplinary field on his interlocutor. Of interest in everything associated with mathematics, for example, only after returning from the field would it make sense to use as a technique, a method of analysis proper to some ethno- $\mathrm{x}$, where $\mathrm{x}$ is one of the academic disciplines that in this author's particular understanding could, for example, be mathematics.
\end{abstract}

Keywords: Ethnography of Knowledge, Ethnoscience, Ethnomathematics, Fundamental Education, Anthropology

Submetido em: 26/06/2021 Aceito em: 18/08/2021 Publicado em: 03/09/2021

\footnotetext{
${ }^{1}$ Doutor em física de sólidos pela Universidade de Montpellier (França). Professor aposentado do Programa de PósGraduação em Ciências Sociais da UNICAMP. Endereço para correspondência: Rua Pinheiro Guimarães 115/Apt. 403B1. 1. CEP: 22281-080 - Rio de Janeiro - RJ - Brasil. E-mail: mdolnecampos@ sulear.com.br.
} 


\title{
Conocimientos académicos en las etnografías de conocimientos locales indisciplinables: etno-matemáticas y otras etno-x
}

\begin{abstract}
Resumen
El artículo propone un debate crítico sobre la separación prejuiciada entre el conocimiento de la academia o ciencia instituida y el conocimiento local de poblaciones de diferentes culturas y organizaciones sociales alejadas de la sociedad circundante. A partir de la etnografía del conocimiento, el material registrado debe ser analizado, ya en la academia, a través de la interacción interdisciplinaria de investigadores de diferentes áreas disciplinares. En el campo, algún investigador particular se enfoca en ciertos dominios del conocimiento que le interesan a la hora de practicar la etnografía sin, sin embargo, proyectar su interés disciplinar en su interlocutor. De interés en todo lo relacionado con las matemáticas, por ejemplo, solo después de regresar del campo tendría sentido utilizar como técnica, un método de análisis específico de alguna etno-x, donde $\mathrm{x}$ es una de las disciplinas académicas que, en la particular comprensión de este autor, podría ser, por ejemplo, matemática.
\end{abstract}

Palabras clave: Etnografía del conocimiento, Etnociencia, Etnomatemática, Educación fundamental, Antropología

\section{Introdução: ciência, etnografia de saberes, etnociência e as etno-x}

O papel de uma etnografia [etn(o)- + (grafia)] de saberes, de outras culturas ou acadêmicos, é compreender e registrar formas pelas quais são construídos os conhecimentos de uma etnia ${ }^{2}$ juntamente com suas técnicas e práticas ao se relacionar com seu entorno natural e social.

Assim como a C\&T têm enorme quantidade de áreas do conhecimento e especialistas, as sociedades tradicionais comportam menos especialistas, mas com envolvimento simultâneo com os domínios natural, social e espiritual. Pela academia se arvorar em deter uma ciência única e universal, sem 'diversidade sociocultural' - seguindo Bruno Latour (1983, p. 172) - será preciso “introduzir inicialmente um pouco de simetria na análise" de diferentes modos de conhecer no interior da academia.

Em busca de mais simetria entre saberes, técnicas e práticas científicas e aquelas pejorativamente ditas 'pré-científicas', Giorgio Cardona apresenta em La Foresta di Piume: Manuale di Etnoscienza (1985), uma ideia do que seria ciência com mais simetria entre distintos saberes:

Como é óbvio, todas as formas de classificação que o homem concebeu para dar ordem e nome ao que vê ao seu redor são substancialmente equivalentes, todas são substancialmente científicas, mesmo que apenas pelo sentido óbvio de que o substantivo scientia deriva de scio, 'sei' e, portanto, qualquer organização de nosso

\footnotetext{
${ }^{2}$ Etnia, do grego ethnos, relaciona-se a povo, nação e compreende um conjunto de indivíduos que comungam um certo número de caracteres materiais, intelectuais e espirituais característicos de uma sociedade, e por ela transmitidos. (CAMPOS e SANZ, 2004, p. 15).
} 
conhecimento, é uma scientia; cada um responde a uma necessidade humana fundamental, a de encontrar-se, medir-se, conhecer-se, sistematizar medindo, conhecendo, ordenando o que está ao seu redor, semelhante ou diferente dele." (CARDONA, 1985, p. 10. Tradução livre do autor).

Dessa scientia, considera-se aqui etnociência uma etnografia de saberes, técnicas e práticas sobre material da ciência 'outra', etnografada no campo. Este material, na volta para a academia é analisado pela etnociência, ou seja, metodologicamente é uma etnografia da ciência do outro, construída a partir do e no referencial disciplinar da academia (CAMPOS, 2002).

Como exemplo, um cientista pratica etno-astronomia ao voltar do campo e trabalhar sobre conhecimentos e práticas de lá sobre o céu, as dinâmicas das relações céu-terra, seus tempos e temporalidades contidos na organização social local. Essa abordagem na academia do material de campo é interdisciplinar, no mínimo, via antropologia, astronomia e etno-astronomia.

Muitas sociedades indígenas têm a necessidade de marcar os tempos sazonais de forma precisa e independente de ações humanas verificando se temporalidades próprias do território correspondem a expectativas. A independência das ações humanas é garantida pela observação dos marcadores celestes de tempo. Este autor, em suas pesquisas entre os Kayapó da Aldeia Gorotire (PA, BR), observou correlações entre constelações reconhecidas nascendo no horizonte pouco antes do Sol nascer e os tempos próprios de outros eventos naturais e sociais do território daquela aldeia.

Nestes meses, o nível das águas do rio começa a baixar, o kubyt (macaco guariba) gordo começa a emagrecer e a 'cantar'. Ocorrem as últimas colheitas de batata, mandioca e banana e começam a se intensificar o lazer e o convívio social nas praias e nas aldeias, com grande dedicação às pinturas corporais. E é no final dessa época que começam as preparações para as puru metoro (festa das roças).

Com o início do mês de agosto, o rio já está baixo (ngô ngrà) com as praias grandes (pyka ti ngrà) e ilhas grandes (apêtê). Aparecem a flor do pente de macaco (akôrãti), a fruta da banana brava ou helicônia (tyryti djô ), o canto do gavião real (kàikwa kam àk), a brocação das roças e a intensificação da pesca que culmina no uso do timbó (akrôre).(CAMPOS, 2006, p. 70; CAMPOS 1987 in HAMU, 1987, p. 44-48)

Tudo isso implica, como se percebe, a necessária análise interdisciplinar (CAMPOS, 2002, p. 56-62) no trato acadêmico dos dados trazidos do campo.

Nessas pesquisas, além dos antropólogos, diversificam-se as especialidades no circuito campo-academia. Como cada um detém uma especialidade ' $x$ ', estes trabalharão sobre o material de campo focando métodos segundo suas etno-x, onde - $\mathrm{x}$ correspondente a uma área do saber acadêmico. Aí inclui-se qualquer área do conhecimento como: etno-matemática, etno-astronomia, etno-biologia, etno-ecologia, etno-pedologia. Estas e outras disciplinas acadêmicas, com ou sem o prefixo etno-, associam-se ao mesmo tipo de análise pela antropologia do saber, como também se estuda especialistas como: xamã, curandeiro, herborista, pescador, pedreiro, borracheiro etc. (Ver Figura 2). 
Assim, procura-se operar análises simétricas sem preconceitos de diferentes saberes, quaisquer que eles sejam.

Ressalte-se que as grafias de etno-x são contrárias à ortografia oficial, pois propositadamente, procurou-se aqui conservar etnociência como área do conhecimento e etno-x como técnicas metodológicas. Técnicas estas de origens disciplinares desenvolvidas no 'estar aqui' da academia para análise do material trazido do campo.

A etnociência praticada no Brasil, tem sido importante nas etnografias do saber entre o trabalho de campo e a academia. Apesar disso persistem preconceitos ligados às suas origens nos EUA, havendo ênfase demasiada na sistemática e taxonômica. Mesmo entre antropólogos brasileiros, há associação pejorativa entre etnociência e o termo do inglês, ethnoscience (CAMPOS, 2002, p. 5674).

Superando as dificuldades, no Brasil centra-se hoje na dinâmica das relações 'humanos/natureza'. Estas incluem abordagens também políticas contrárias a preconceitos e opressões contra populações tradicionais e indígenas ${ }^{3}$.

\section{Ciências Naturais e Sociais no encontro com o outro: dupla e tripla liminaridade}

Pesquisadores, na academia e no campo, enfrentam obstáculos epistemológicos que podem se apresentar como importantes desafios na sua superação (BACHELARD, 1996). Na academia, a interdisciplinaridade já é um desafio pelas epistemologias próprias de cada área do conhecimento, no árduo e gratificante, diálogo entre distintas cosmovisões. Em algumas das ciências sociais, pesquisadores servem-se da etnografia que, além do seu arcabouço teórico, uma vez no campo é literalmente a prática da escrita sobre pessoas e grupos sociais com os quais se interage. Roberto Cardoso de Oliveira (1996) considera o trabalho do etnógrafo com três momentos estratégicos: olhar, ouvir, escrever. Claro que ele é acompanhado de artefatos para concretizar esses três momentos. As inúmeras etapas implicam uma circulação entre o campo e a academia na busca de esclarecimentos interdisciplinares quando na academia. Circulação essa que é caracterizada por Clifford Geertz (1989) através de alternâncias entre 'estar lá' (no campo), 'estar aqui' (na academia) e 'escrever aqui' (na academia).

$\mathrm{Na}$ pesquisa etnográfica entre grupos locais com diferenças marcantes com a sociedade envolvente, impõe-se um intenso esforço de abertura para o diálogo. Como as visões do mundo e cosmovisões podem ser muito distintas entre cada um dos modos de vida em diálogo, o caminho para

\footnotetext{
${ }^{3}$ Um exemplo é o Projeto Kayapó na Aldeia Gorotire (Pará), desenvolvido a partir do Museu Paraense Emílio Goeldi (MPEG) nos anos 1980 com cerca de vinte pesquisadores. Projeto coordenado pelo saudoso Darrell Addison Posey (biólogo e antropólogo). Marcio D’Olne Campos trabalhou, marcadamente, sobre saberes das relações céu-terra. Ver Denise Hamu (1987).
} 
a interlocução ocorre com a facilitação da comunicação a partir de cada interlocutor no seu referencial sociocultural de fala, seu ponto de vista. Para que a relação seja marcada pela 'dialogicidade' essência da educação como prática da liberdade, como discute Paulo Freire no capítulo três da Pedagogia do Oprimido (1981), - é necessário um ajuste dos referenciais para o diálogo, ou seja, a partir de que lugar, naturalidade, nacionalidade, cultura, ponto de vista, cada um se expressa. Por exemplo, numa primeira conversa nossa com um hindu, é preciso que partamos do fato de que um abano de cabeça quase no sentido horizontal na Índia expressa um sim categórico e satisfeito, e exatamente o contrário para nós.

Os diálogos entre diferentes áreas do conhecimento, nem sempre são tarefas fáceis de se empreender na academia. Há dificuldades entre as ciências naturais e ciências sociais e tremendos esforços para o ajuste dos referenciais do diálogo. No trabalho etnográfico, predominam saberes locais próprios e muito distintos entre as cosmovisões locais e as da academia, o que complexifica as situações. Na compreensão desse problema, recorre-se ao antropólogo Edmund Leach e seu artefato da teoria dos conjuntos.

Edmund Leach (1978, p. 43-46) usou diagramas de Venn-Euler da teoria dos conjuntos para discutir 'A Ordenação Simbólica de um Mundo Criado pelo Homem: Limites de Espaço e Tempo Social'. Leach menciona fronteiras ou limites como 'terras de ninguém' - sem dimensão. Com isso “O princípio de que todos os limites são interrupções artificiais do que é naturalmente contínuo e de que a ambiguidade implícita no limite é por si uma fonte de ansiedade, aplica-se ao tempo e ao espaço" (LEACH, 1978, p. 44), especialmente quando referidos a aspectos sociais.

Numa cerimônia de casamento, p. ex., conceitualmente, uma mudança de status de 'solteiro para casado' é simplesmente uma troca de categorias, troca de um status social para outro. Acontece que, no nível da ação, a troca necessita de um ritual, cruzamento de fronteiras sociais que acontece no 'tempo de ninguém', o que corresponde justamente à interseção entre categorias temporais. A fronteira, ou os limites indefiníveis representados na interseção, tomam importância e valor especial: ritual, 'sagrado', tabu', momento de transição ou de indefinição entre dois estados conhecidos momento ritual. Em conclusão, a interseção no diagrama de Venn-Euler é uma zona de liminaridade sujeita a tabu. Aqui se referiu apenas a limites temporais, mas sem maiores detalhes, o caso de fronteiras espaciais tem um bom exemplo ao se pensar nessa linha imaginária que divide o espaço entre países. Uma liminaridade ocorre se alguém pisar numa linha fronteiriça de tal modo que calcanhar e artelhos do mesmo pé estejam situados em países distintos.

Para interagir com e compreender os saberes de outras culturas, não podemos nos prender a amarras disciplinares como interlocutores querendo interagir e observar essas populações. Entre a sociedade tecnocientífica e uma sociedade indígena mais isolada, p. ex., não existe isomorfismo 
'disciplinar' entre as especialidades respectivas. São diferentes cosmovisões - que já ocorrem na academia - por um lado, entre as fronteiras quase intransponíveis entre ciências naturais e sociais numa interseção de dupla liminaridade (Figura 1a). Se cientistas naturais e sociais interagem no campo com outra cultura, a liminaridade agora se torna tripla entre a academia e outra cosmovisão (Figura 1b). Daí o cuidado para que não se explicite ferramentas disciplinares no campo gerando imposições e conflitos com os próprios saberes locais que se quer conhecer.

No caso da tripla liminaridade, sendo quase impossível haver isomorfismo entre as especialidades dos domínios acadêmico e pesquisado, os acadêmicos são, com frequência, obrigados a articular-se interdisciplinarmente (CAMPOS, 2002, p. 56-62) para melhor compreender os saberes e técnicas do outro contexto sociocultural. Sobre a dificuldade ou impossibilidade de encontrar isomorfismo entre especialistas dos meios acadêmico e de outra sociocultura, a Figura 2 esquematiza o problema.

Figura 1 - 1a. Zona de interseção de dupla liminaridade entre ciências naturais e sociais na academia. 1b. Zona de tripla liminaridade no trabalho de campo com outra sociedade com outra cultura.
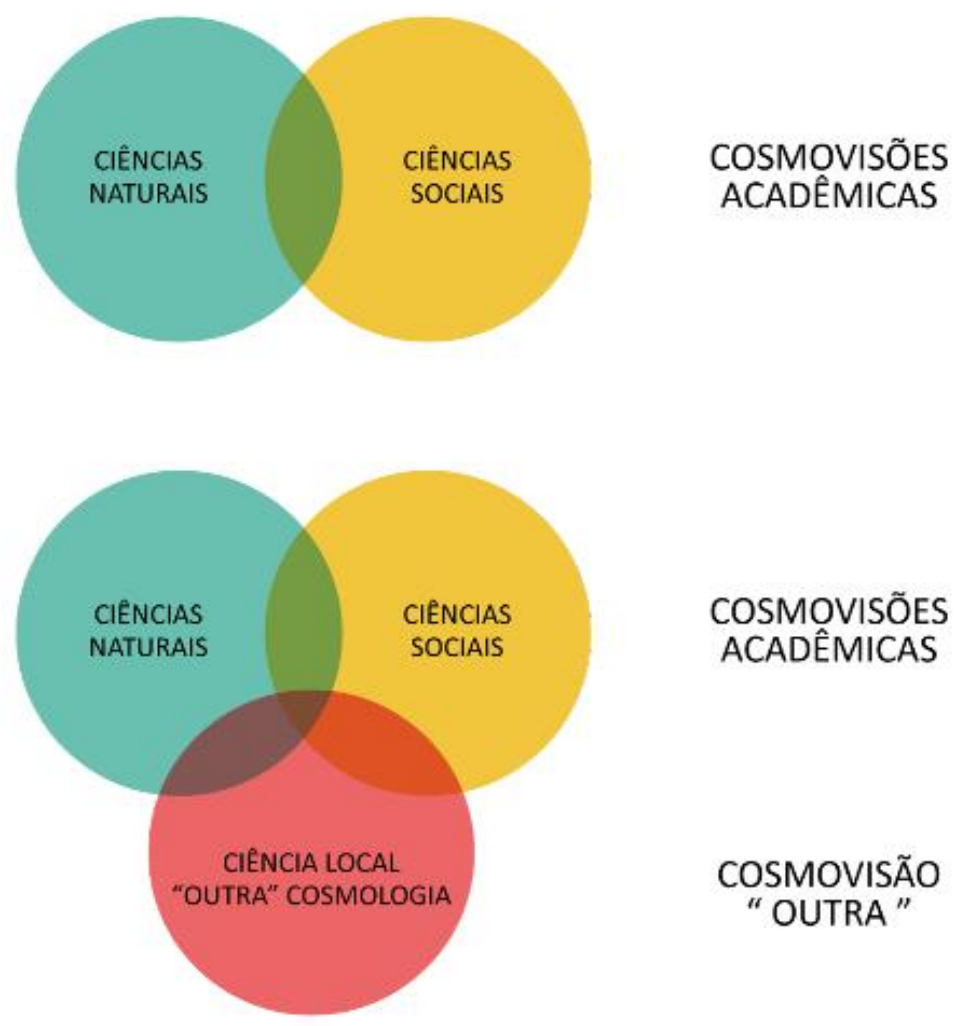

\section{COSMOVISÕES} ACADÊMICAS

Fonte: elaboração própria. 
Figura 2 - Difícil isomorfismo entre especialidades da academia e especialidades de sociedades e culturas distintas da sociedade tecnocientífica envolvente.

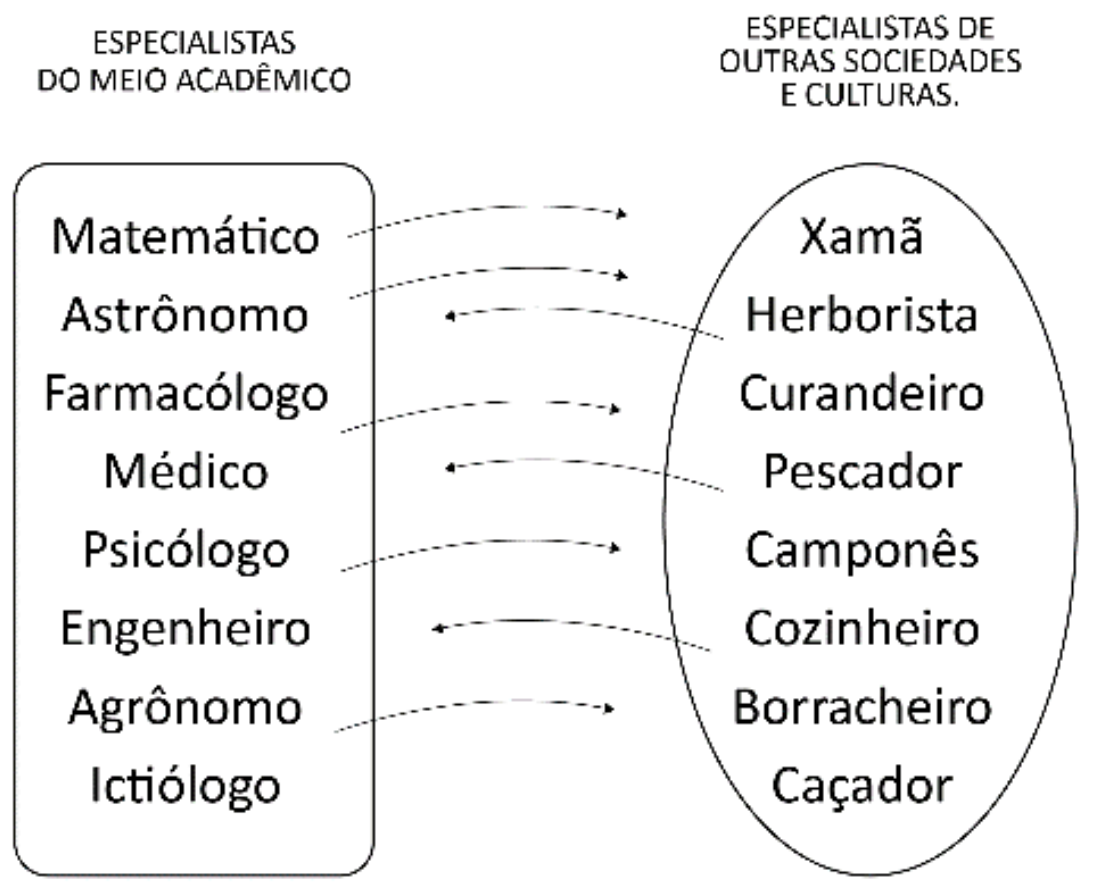

Fonte: elaboração própria.

Por certa comodidade de escrita e guardadas as ressalvas, no decorrer deste texto foram usados alguns termos como 'outro', 'outro saber', 'outra cultura' para diferenciar das características da sociedade envolvente mergulhada na $\mathrm{C} \& \mathrm{~T}$ e por isso, às vezes denominada de tradição científica apesar desse termo deixar de lado uma grande parcela de excluídos. Essa ressalva se justifica ainda mais pelo fato de que a partir do início dos anos 1980, intensificou-se o número de integrantes das ditas 'populações nativas', 'tradicionais', quilombolas e especialmente indígenas que, com seu acesso às universidades, inaugurou uma geração de 'antropólogos nativos' que embora, agora universitários, prosseguem referindo-se e defendendo a preservação das diferenças na dinâmica própria de seus lugares de origem. Diferenças e o necessário respeito a elas existe, não se tratando em absoluto de um contínuo entre costumes e saberes de sociedades locais e globais. Evidentemente, em diversos contextos de encontros interculturais - sejam eles dialógicos, tensos ou opressores -, essa nova realidade passou a dificultar e relativizar o uso da antinomia 'nós' e 'eles', ou 'nós' e os 'outros'. O pensamento, porque individual, é sempre único como processo, embora resulte socialmente numa enorme diversidade de produtos socioculturais com seus sistemas próprios de expressão - um espetro 
descontínuo de saberes diferentes e diferenciáveis, sendo cada um deles uma scientia, como indica Cardona (1985, p. 10).

Clifford Geertz (1999) reflete criticamente sobre a ideia do 'outro', acrescentando aspectos importantes sobre o que foi referido no parágrafo acima:

\begin{abstract}
...pensamento é múltiplo como produto [diversidade sociocultural] e singular como processo, o que se constituiu como importante paradoxo nas ciências sociais gerando teorias em todas as direções, algumas delas razoáveis, mas a natureza do paradoxo tem sido vista como relacionada com um quebra-cabeça de tradução, ou seja, o de como um significado num sistema de expressão é expresso em outro... hermenêutica cultural, não mecânica conceptiva.

(...) Somos todos nativos agora, e qualquer outra pessoa que não seja imediatamente um de nós é um exótico. O que antes parecia ser a questão de saber se selvagens poderiam distinguir fato de fantasia, agora parece ser a questão de se saber como outros, de além-mar ou no corredor, organizam seu mundo significativo. (p. 226), [grifos do autor].
\end{abstract}

Sermos 'todos nativos agora' abre caminhos para a etnografia das sociedades complexas na organização de significados em contextos antes não pensados, como aqueles da própria instituição social da ciência (C) e da tecnologia (T) consagradas no binômio C\&T. Binômio esse ao qual há quem pretenda atribuir "neutralidade científica", balela nunca existente que cai por terra, entre outros fatores, com o advento, via Bruno Latour, da etnografia dos laboratórios. Etnografia realizada de forma semelhante ao modo como se processam, articulando emoção e razão, as etnografias nas aldeias indígenas. Assim se etnografou 'A Vida de Laboratório' no contexto cotidiano, objetivo e subjetivo, da 'produção dos fatos científicos' no Laboratório de Neuroendocrinologia do Instituto Salk na Califórnia (LATOUR; WOOLGAR, 1997).

\title{
3. Do evolucionismo social à diversidade cultural da moderna antropologia
}

É fundamental que se reconheça, respeite e valorize cada componente da diversidade sociocultural na superfície da Terra - que é redonda, diga-se de passagem.

A história e, sobretudo, a antropologia, só passaram a assumir a diversidade sociocultural ao final do Século XIX. Por isso seguem considerações sobre o horror das crenças no evolucionismo social unilinear que considerava a dita 'humanidade' como portadora de uma só sociedade e uma só cultura. Até hoje usos abusivos do termo 'humanidade' escondem a evidência de que pessoas, sociedades e culturas são diferentes, ainda que partam da mesma espécie humana.

Anteriormente à moderna antropologia marcada pela diversidade cultural,+ havia a crença de que sociedades humanas obedeciam a uma evolução unilinear caracterizada 'historicamente' em três estágios: selvageria, barbárie e civilização. Como os intelectuais não acreditavam em observação 
participante $^{4}$, as duas categorias inferiores eram imaginadas - e não observadas - pelos 'civilizados' numa conveniente distancia social. Como já se falava em evolução, poder-se-ia pelo menos representar num eixo dos tempos a evolução das sociedades humanas. Isso estaria totalmente fora de consideração e não se pensava em diversidade cultural, embora se aceitasse tácita e estaticamente qualquer forma de desigualdade.

Em 1851, Charles Darwin propôs a teoria da evolução biológica a partir da origem das espécies. A partir de 1870, alguns cientistas sociais propunham o evolucionismo social unilinear na ânsia cientificista de trazer as pseudo certezas das ciências naturais para as ciências humanas e sociais. Não tardaram as críticas e Franz Boas estava entre os pioneiros com seu artigo 'Os limites do método comparativo em antropologia' (1896). Sua crítica contestava o caráter unilinear com que 'civilizados' imaginavam comparavam-se a selvagens e bárbaros fadados - se evoluíssem - a tornarem-se semelhantes àqueles por via de uma única 'trilha' sociocultural.

Com Franz Boas e o fim da evolução social unilinear, se instaura a reconsideração dos humanos constituindo-se em diferentes sociedades e diferentes culturas na grande diversidade sociocultural do Planeta. Assim surge a moderna antropologia.

O referencial, de observação para as imaginações comparativas era o da civilização que classificada como tal, se mantinha olhando para os "de baixo" a partir de um referencial dito civilizado, imutável, estagnado, mas sempre competente para entender/imaginar e teorizar sobre o que se passava com os "outros". Estes, de subalternidade imposta, mantinham-se perfeitamente integrados na antinomia chave - "nós/ "outros". Antinomia essa da dominação e colonização que embora, com a descolonização hoje "inexistente", ex-colonizados ainda guardam - arraigada na memória individual de corpo e alma assim como na memória social - o que se denomina colonialidade: uma reconfiguração velada da antinomia: “nós/ "outros” (LANDER, 2005). Daí originaram-se os movimentos individuais e sociais que hoje lutam e refletem pela decolonialidade 5 .

É importante frisar o caráter de dominação em quaisquer dos contextos dessa história colonização e colonialidade. Se trocas interculturais aconteciam, estas não se aproximam de trocas dialógicas no sentido freireano. Essas trocas, veladas ou não, estão mais para "bancárias" (FREIRE, 1981, p. 76) com tensões do tipo opressores sobre oprimidos.

\footnotetext{
${ }^{4}$ Metodologia de trabalho de campo na qual o etnógrafo apreende através da observação e participação na vida social das pessoas e do grupo em estudo. Sugere-se ler os dez mandamentos sobre 'observação participante' propostos por Licia Valladares (2007). Licia se inspirou em William Foote Whyte, sociólogo que se dedicava à pesquisa etnográfica em contextos urbanos: WHYTE, William Foote. Sociedade de esquina: a estrutura social de uma área urbana pobre e degradada. Rio de Janeiro, Jorge Zahar, 2005.

5 'Ger 'Grupo modernidade/colonialidad' em verbete da Wikipedia. Disponível em <https://es.wikipedia.org/wiki/Grupo_modernidad/colonialidad >. Acesso em 15 fev. 2021.
} 
Portanto, a colonização explicitada por países colonizadores, que aparentemente se extinguiu na independência de antigas colônias, tomou a forma contemporânea da colonialidade arraigada individual e socialmente nas nações agora independentes, assim como também entre populações que experimentam condições subalternas de vida em diversas regiões do Planeta. Exemplos não faltam e basta citar a situação de refugiados em países mais "desenvolvidos”, as tensas relações Norte/Sul até hoje e desde a Guerra de Secessão (1861-1865) nos EEUA, e as tensões contemporâneas na fronteira México-EEUA (BAEZ LANDA, 2019).

Os resquícios do evolucionismo social unilinear existem e se representam até hoje permeados de etnocentrismo, racismo e outros preconceitos. Ouve-se ou lê-se, por exemplo, frases como 'A cultura do índio é baixa' a qual foi pronunciada pelo então ministro do exército durante o Governo José Sarney, General Leônidas Pires Gonçalves. ${ }^{6}$

Preconceitos em relação a supostas inferioridades, mas que, de fato, residem na negação do reconhecimento das diferenças entre "brancos", negros, índios, ocidentais, orientais etc., fazem com que as diferenças $(\neq)$ sejam apenas reconhecidas por pseudo superiores, não como deveriam, mas de fato como desigualdades entre pessoas, grupos e hierarquias próprias de instituições. Desigualdades essas que na linguagem matemática se representariam pelos dois símbolos de maior (>) ou de menor (<) - nunca pela igualdade (=). Vale uma alusão ao lema da Revolução Francesa: Liberdade, igualdade, fraternidade. Quem dera!

Para as elites, parece mais 'fácil' conviver e aproveitar-se de serviços de subalternos por uma conveniente distância social integrada a diferenças de classes e desigualdades econômicas.

Com isso, passa-se agora à discussão de formas mais convenientes para se conhecer outras culturas pela etnografia das diferentes formas de saber construídas a partir de diferentes leituras do mundo.

\section{4. 'Científico', 'pré-científico' e saberes locais - entre simetrias e assimetrias}

Na Grande divisão entre os saberes 'científico' e 'pré-científico', Bruno Latour (1983a) considera simetrias e assimetrias na comparação crítica e irônica entre esses tipos de saberes para pensar em 'Como redistribuir a 'Grande Divisão'7 entre saberes 'acreditados' e 'desacreditados'. Essa

\footnotetext{
${ }^{6}$ Outros aspectos dessa discussão, incluindo antropologia biológica e medicina legal, podem ser encontrados em "O que é antropologia e etnografia?' (CAMPOS, SANZ, 2004, p. 14-28).

${ }^{7}$ Originalmente publicado sob o título Comment redistribuer le Grand Partage? (LATOUR, 1983), foi traduzido no mesmo ano no Brasil por "Como redividir a Grande Divisão" (1983a). No lugar de "redividir', o termo 'redistribuir' parece ser preferencialmente mais fiel à ideia do original francês.
} 
divisão nos ronda cotidianamente nas recorrentes leituras do mundo ${ }^{8}$ que deve-se sempre empreender por toda a vida.

A ironia crítica no termo 'pré-científico' é evidente considerando-se que Latour defende a simetria como princípio de análise entre quaisquer formas diferentes de saber existentes. Aqui o irônico 'pré-científico' parece caracterizar o saber de um período anterior ao advento da 'ciência' ou da aplicação do 'método científico'. Assumir essa visão de 'ciência' contraria nitidamente a interessante e simétrica ideia de ciência (scientia) de Giorgio Cardona (1985, p. 10).

No exercício da antropologia das ciências e técnicas, Latour se propõe a nenhum crédito atribuir para qualquer processo ou produto pautado pela Grande Divisão. De onde quer que se originem ou atuem, os produtores de saber devem se submeter a um mesmo tipo de investigação etnográfica, sejam eles cientistas, professores, feiticeiros, intelectuais do sertão, engenheiros ou botânicos.

Em vez de introduzir desde o início, como evidência primeira, a existência de um abismo entre as maneiras científicas de conhecer e as outras, era melhor chegar a esse abismo, se existisse, depois da pesquisa e somente depois que todas as possibilidades de explicação mais simples tivessem sido esgotadas. Dessa forma, essa divisão entre as ciências e o resto, se existisse, estaria mais bem fundamentada. (LATOUR 1983a, p. 169)

Em 1992, no Rio de Janeiro, realizou-se a Eco-92 ou Conferência das Nações Unidas sobre o Meio Ambiente e Desenvolvimento (CNUMAD). Ao longo dos anos 1990 era intensa a discussão sobre sustentabilidade, sobretudo relativa ao consumismo a agressão à natureza em ambientes urbanos. Pouco se discutia, como ainda hoje, outras formas de sustentabilidade como a sociocultural. Ao final da década, Jonathan Murdoch e Judy Clark discutiram a sustentabilidade do conhecimento (MURDOCH; CLARK,1999). Referindo-se a críticos da concepção assimétrica de ciência, mostraram que entre ciência instituída e saber local não existiria diferença apenas pelo fato de que a primeira tivesse um acesso superior à 'realidade', mas sim pelo fato de que essa é mais poderosa e capaz de deslocalizar-se para atuar longe.

Murdoch e Clark (1999, p. 119-122) chamam a atenção sobre a forma eminentemente local de produção da ciência e o papel crucial do laboratório. Isso coloca em questão o debate 'global/local', pois enquanto a produção de ciência é local, sua difusão pelos atores sociais é global.

A façanha consumada da nova sociologia da ciência é tornar a ciência esplendidamente transparente por um efeito do poder. Estudos da 'ciência em ação' tornam-se o estudo da ciência enquanto prática de poder, na medida em que centros particulares de conhecimento (geralmente laboratórios) atuam em outros tempos e outros lugares; breve, a problemática torna-se a de como os cientistas agem à distância (p. 121).

${ }^{8}$ Ver "Leitura da palavra...leitura do mundo" (FREIRE; CAMPOS, 1991). 
Nós devemos examinar como alguns atores ganham o direito de falar por outros e mostrar como eles impõem definições particulares e papeis sobre esses outros. Para ter sucesso um ator deve colonizar outros atores-mundo. (p. 122) [grifos do autor].

Latour é também enfático ao afirmar que um resultado ou um fato científico é, em geral, produzido em um laboratório e, portanto, sempre gerado localmente. Considere-se que este fato, estando ainda no laboratório, é um fato 'mole'. Assim que esse 'fato mole' for reconhecido pela comunidade científica e mais tarde pela população, chega-se, com esforço humano e financeiro, ao status de fato 'duro'.

Isso implica em que, para ter sucesso em 'endurecer' um fato e fortalecer as ligações, entra em jogo o mundo-de-atores responsável por deslocalizar a ciência e seus fatos dos laboratórios, instituí-la e universalizá-la. Nisso é preciso que atores sociais tenham colonizado outros mundos-deatores, incluídos os setores chave da comunidade científica. Evidentemente, os recursos financeiros e de energia a despender envolvidos na instituição social da C\&T para essa tarefa, são fabulosos (LATOUR, 1983a, p. 181).

O que pensar sobre as outras formas de ciência e técnica locais, próprias de sociedades tradicionais?

Uma vez efetivada a propagação de um fato, esse empreendimento reforça-se pela amplitude de 'horizonte' ou 'visão de grande angular' da propagação pela compressão espaço-tempo. O que o empreendimento não cede lugar é à inclusão. É distinguir a diversidade das populações tradicionais. Quando distingue, escapa pelo uso de explicações sociais, culturais ou circunstanciais sobre o saber local. Isso ocorre apenas quando o saber do outro é supostamente reconhecido como falso - antes mesmo de ser conhecido. Sendo verdadeiro, não haveria necessidade de explicação social ou cultural: a verdade é suficiente para explicar-se a si mesma. (LATOUR, 1983a, p. 172).

Cada estudo traz assim a prova de que os fatos científicos não são o produto de circunstâncias culturais determinadas. Por isso surge a questão que não se pode evitar ao lê-los: como nós, ocidentais, fomos capazes de inventar uma forma de conhecimento tão radicalmente original que ela escapa a todas as condições culturais de produção? A Grande Divisão existe, C.Q.D. Milagre da razão universal que escapa das circunstâncias culturais. Não é surpresa esse C.Q.D. Ele está totalmente contido na questão e na ausência de simetria aceita no início entre os vencedores e os vencidos da história do saber. (p. 172)

Latour (1983a), ao discutir simetria e suas contradições, percorre alguns exemplos como os da monografia 'Bruxaria, Oráculos e Magia entre os Azande' (EVANS-PRITCHARD, 1978). Esta monografia explicita contradições do apelo a 'explicações sociais, culturais ou circunstanciais' pelos preconceitos contra saberes locais - os saberes 'desacreditados' de sociedades tradicionais. Para isso, Latour apresenta um esquema ilustrativo na Figura 3, e comenta: 
O exemplo já é clássico (ver figura 3). Segundo Evans-Pritchard, uma conclusão lógica que os Azande poderiam tirar ('dado que um membro do clã é declarado feiticeiro, todos os membros do clã são feiticeiros') é desviada, porque se choca com um preconceito social firmemente estabelecido ('todo mundo sabe bem que o clã todo não pode ser feiticeiro'). O resultado é um desvio em relação à lógica e um compromisso entre as condições sociais e a lógica ("existem feiticeiros frios' [que não têm êxito como feiticeiros]). Conclusão do analista: as aptidões lógicas dos Azande não estão ausentes, mas elas são contrariadas por preconceitos culturais e nunca podem se desenvolver livremente (LATOUR,1983a, p. 173).

Figura 3 - Exemplo da antropologia simétrica de Bruno Latour. Um antropólogo inglês entre os Azande e um 'antropólogo Azande' entre os ingleses dos dois lados do plano de simetria.
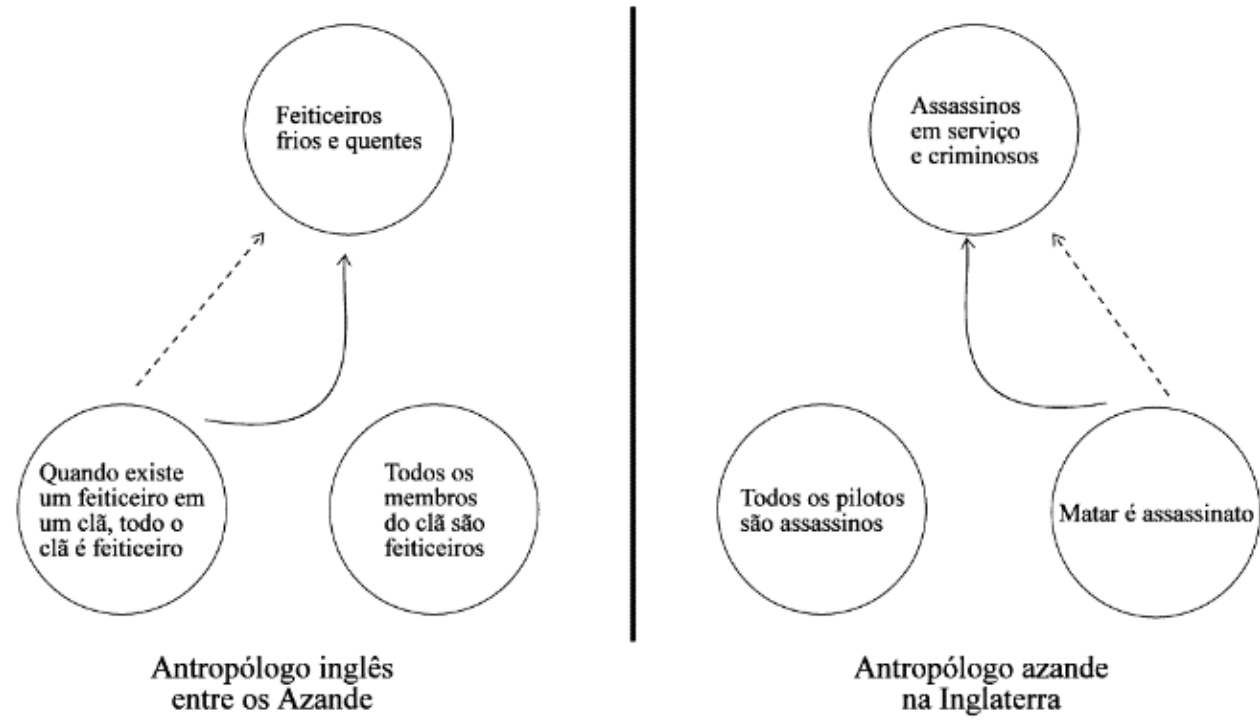

Fonte: (LATOUR, 1983a, p. 173)

Latour (1983a), faz referência a seu colega David Bloor para aplicar o que este chama 'princípio de simetria' através do qual um antropólogo imaginário Azande estuda 'ocidentais' do mesmo modo como estes costumam estudá-los em sua aldeia. (BLOOR ${ }^{9}, 2009$ apud LATOUR, 1983a, p. 174).

A partir do relato desse etnólogo imaginário, uma conclusão lógica que os ocidentais poderiam tirar ('uma vez que toda pessoa que mata voluntariamente é um assassino, os pilotos de bombardeios são assassinos') está desviada porque ela contraria um preconceito social fortemente estabelecido ('todo mundo sabe que os pilotos de bombardeios não são assassinos'). O resultado é um desvio em relação à inferência e um compromisso entre as condições sociais e a lógica ('existem assassinos inocentes'). Conclusão do analista Azande: nessa cultura 'as pessoas não têm nenhum interesse prático nas conclusões lógicas e [...] preferem conservar sua selva

\footnotetext{
${ }^{9}$ Em seu artigo, Bruno Latour (1983a) se refere à edição francesa do livro de David Bloor (1983, p. 160). Na edição brasileira a citação de Latour corresponderia à página 207 da seção 'A lógica Azande e a ciência ocidental' (BLOOR, 2009, p. 207-219). As aspas simples na citação que se segue correspondem ao que Bloor escreve e é citado por Latour.
} 
metafísica, por medo de ver ameaçadas suas instituições repressivas'. (LATOUR, 1983a, p.174).

Sem aprofundar as análises de Latour sobre o exemplo, seguem alguns de seus comentários. O desvio em relação a uma inferência lógica está em 'todo mundo sabe bem', que eliminaria os círculos próximos ao plano de simetria com argumentos que embora possam parecer lógicos, têm pouca chance de ocorrer. Argumentos esses impostos por aquele que mesmo ignorando a cultura, entra em contato com ela. "As palavras 'irracional', 'ilógico', 'mágico', são acusações; elas são o efeito do choque entre sistema de referência, não dizem nada sobre as aptidões lógicas ou as formas de raciocínio de nenhuma cultura em particular" (LATOUR, 1983a, p. 174).

Com isso, assumimos dos dois lados as linhas retas pontilhadas, deixando de lado as linhas curvas e os dois círculos próximos do plano de simetria pelos quais essas linhas 'se atraem'.

A lógica, que até agora era apenas influenciada pela sociedade, tornou-se uma sociológica. O objetivo dessa retificação dos saberes não é se deleitar no relativismo, como nos acusam erroneamente, mas de permitir uma investigação livre de preconceitos sobre os saberes desacreditados, bem como sobre os saberes acreditados. O ganho não é filosófico, é sobretudo empírico. (LATOUR, 1983a, p. 174).

Espera-se que algumas das questões discutidas contribuam no trilhar da via da 'etnografia de saberes e técnicas' para, não só melhorar a interlocução no campo, como também contribuir para o reforço do poder reivindicatório local. Assim perceber-se-ia melhor a importante interseção entre sociedades tradicionais e a 'sociedade moderna'. Interseção essa onde importam muito os saberes e técnicas tradicionais na sua contribuição para o aperfeiçoamento das condições de sustentabilidade nas relações humanos-natureza e sociedade-natureza.

\section{Etnografia de saberes, técnicas e práticas, etno-x e etnomatemática}

A etnociência, embora dotada de considerável polissemia, guarda a ideia de como etnias constroem seus conhecimentos - ou suas scientiae. Construção essa que ocorre no convívio social das interrelações e com a natureza sendo o espaço transformado pela ação humana na relação com matérias primas do mundo natural.

Pode-se considerar impossível o isomorfismo (Figura 2) entre especialistas da ciência instituída pela Grande Divisão e, por outro lado, os especialistas do 'saber popular', do 'saber rural' e dos saberes locais, como o dos indígenas. Esse simples fato mostra a dificuldade para um 'cientista se representar a scientia de outra etnia sem projetar elementos da sua área acadêmica de conhecimento sobre o outro, interlocutor sendo também observado. Deste se quer mais é observar, ouvir e compreender sua cultura. 
Darrell Addison Posey (1986) sugeria uma 'metodologia geradora de dados' que propõe mais simetria e dialogicidade nas interlocuções do campo. Nosso ajuste dos referenciais do 'outro' permite que a compreensão se realize a partir daquele universo de saber estudado.

Questionar, pura e simplesmente, conduz à inibição do fluxo de informações por parte do informante. A pergunta: 'quantos tipos de X existem?' presume que X é uma categoria cross-cultural válida e que existem tipos de $\mathrm{X}$ identificados e nomeados em todas as culturas. 'Esta é a larva da borboleta X?' supõe a noção de metamorfose que pode deixar de explicar a ontogenia em todas as sociedades. (...) De um modo geral, quanto mais aberta a pergunta, isto é, menos restritiva, maior é a liberdade deixada ao informante para responder segundo sua própria lógica e conceitos. Melhor dito, quanto menos perguntas, melhor é. Recomenda-se por isso, uma metodologia 'geradora de dados'. Ou seja, na medida em que o informante propõe tópicos e explicações corre-se menos risco de prejudicar a informação. (POSEY, 1986, p. 23-24).

Captar o universo de significados de outra cultura exige um esforço incessante de captar os fenômenos a partir dos referenciais dessa cultura a das suas categorias nativas. Ao mesmo tempo vaise, com dificuldades, pondo de lado as ferramentas disciplinares que devem ir dando lugar aos saberes, técnicas e metodologias do 'outro'. Desse 'estar lá', segue-se o 'estar aqui' e o 'escrever aqui'. Nesse processo há a presença constante da tradução como sugere Geertz: fazer com que um significado expresso no sistema 'de lá' do campo seja expresso no sistema 'daqui' da academia.

Pelas considerações acima, no corpo de saberes do outro não há espaço para qualquer etno-x, já que x é uma disciplina da academia. Por exemplo, este autor foi por vezes ao encontro dos Kayapó da Aldeia Gorotire para a interlocução no intuito de aprender como eles praticam e elaboram sua scientia. Focalizava o que eles sabem das relações céu-terra, dos objetos e entidades naturais e espirituais, das noções de espaço e de tempo e temporalidades ao longo dos dias, meses (luas), estações, anos e gerações. De volta com o material do campo, aí sim, há o recurso a disciplinas como, p. ex., astronomia e o diálogo com os pares de outras especialidades, trabalhando-se o material de campo, p. ex., com um método etno-astronômico ou outro de análise.

Parece um absurdo muito grande dizer-se que no exemplo acima pesquisou-se a 'etnoastronomia dos Kayapó'! Isso não existe entre os Kayapó, como também não existe qualquer uma das etno-x. Essa é uma área do saber da academia e não dos Kayapó que têm outras especialidades.

Para marcar os problemas do etnocentrismo, nos anos 1980 quando professor no Instituto de Física da Universidade Estadual e Campinas (UNICAMP), o autor já se dedicava à etnociência que despertava interesse de colegas, embora houvesse visões discutíveis. Nisso ocorreu um comentário entusiasta e inadvertido de um colega sobre uma etno-x. Num dos sítios, quase no limite da zona rural de Campinas, eis que ele encontra uma senhora que no seu quintal fabricava 'sabão de cinzas' (cinzas, 
gordura e água). De volta ao 'estar aqui', ele conta o que encontrou e surpreso exclama: 'Veja você! Até aquela senhora faz química!'.

Essa constatação preconceituosa e digna de uma 'Grande Divisão' é marcada de ambiguidade entre o entusiasmo pelo encontro com um saber popular e o juízo da ignorância por um padrão de saberes acreditados, como os da química. A frase delatora - 'até aquela senhora faz química!' - sobre saber fazer sabão de cinzas, menciona algo que 'nós' poderíamos saber fazer tão bem quanto a senhora e, além disso, usando a ciência química. Ou seja, o termo 'até', eivado de preconceito, parece servir, ainda mais para enaltecer o valor da ciência química que não é para qualquer um.

O preconceito contra 'outros saberes' é tão forte assim como a valorização das nossas ciências como universais que faz com que alguns digam que vão ao campo pesquisar 'a etno-astronomia dos Kayapó', a 'etno-matemática dos Rikibatsa' ou qualquer etno-x de uma etnia. Observar os astros ao logo do tempo e as relações céu-terra (CAMPOS, 2006), contar, medir e saber lidar com espaço e suas dimensões (FANTINATO, 2004); relatos etnográficos como esses, é o que se pode desvelar de outra cultura por uma etnografia de saberes técnicas e práticas para uma vez na academia, trabalhar interdisciplinarmente com técnicas metodológicas de uma etno- $\mathrm{X}$

Entre as 'etno-x', o termo etnociência (ethnoscience) surge pelo menos desde 1957; mas o uso do prefixo 'etno-' resulta de muito antes, como evidencia a série escavada por Giorgio Cardona (1985, p.15) num espólio da literatura sobre o assunto e representado no Quadro 1.

Quadro 1 - Aparecimento de novas etno-x ao longo dos anos.

\begin{tabular}{|l|c|}
\hline etnoconquiliologia & 1889 \\
\hline etnobotânica & 1896 \\
\hline etnozoologia & 1914 \\
\hline etnogeografia & 1916 \\
\hline etnobiologia & 1935 \\
\hline etnoherpetologia & 1946 \\
\hline etnociência & 1957 \\
\hline etnomicologia & 1960 \\
\hline etnoictiologia & 1967 \\
\hline etnoornitologia & 1969 \\
\hline etnomineralogia & 1971 \\
\hline
\end{tabular}

(CARDONA,1985, p. 15)

Nota-se que o Quadro 1 não contém o termo etnomatemática, usado e consolidado até hoje por Ubiratan D'Ambrosio (1990, p. 5-6) como "a arte ou técnica de explicar, de conhecer, de entender nos diversos contextos culturais".

Curioso é que na caracterização d'ambrosiana de etnomatemática não apareça explicitamente o termo matemática, uma das disciplinas ' $\mathrm{x}$ ' do ponto de vista do presente autor. Para este, a etnomatemática referida a d'Ambrósio não pode ser considerada uma etno-x. Naquela definição de 
etnomatemática, a ausência da disciplina matemática poderia se justificar se a considerarmos associada a termos como mathematikós que do grego se relaciona a científico ou 'inclinado a aprender', ou mathêma, relativo à 'ciência'.

Por argumentos etimológicos, D'Ambrosio (1990) procura uma definição bastante genérica e não disciplinar do termo que quase transcende uma etnociência indo além dela: "Nessa concepção, nos aproximamos de uma teoria de conhecimento ou, como é modernamente chamada, uma teoria da cognição." (D'AMBROSIO, 1990, p. 6). Por argumentos etimológicos e prescindindo de qualquer disciplina, inclusive a matemática, sua "postura teórica" contém:

...etno é hoje aceito como algo muito amplo, referente ao contexto cultural, e portanto, inclui considerações como linguagem, jargão, códigos de comportamento, mitos e símbolos; matema é uma raiz difícil, que vai na direção de explicar, de conhecer, de entender; e tica vem sem dúvida de techne, que é a mesma raiz de arte e de técnica. Assim, poderíamos dizer que etnomatemática é a arte ou técnica de explicar, de conhecer, de entender nos diversos contextos culturais. (D'AMBRÓSIO, 1990, p. 5)

A presente discussão a partir de uma referência de trinta anos passados se justifica por ela ser, pelo menos até $2020^{10}$, sistematicamente usada pelo autor e seus seguidores quando se trata da concepção de D'Ambrósio sobre a etnomatemática, resumida por ele também num artigo em 2018:

Porque não ethno [para um grupo comumente aceito de mitos e valores de comportamentos compatíveis] + Techné [para maneiras, artes, técnicas] + mathema [para explicar, compreender, aprendizagem]. Minha proposta é um programa de pesquisa para entender os ticas de mathema em diferentes ethnos. Os três juntos formam etno + mathema + ticas ou, como ele iria soar muito melhor, etnomatemática. (D’AMBROSIO, p. 28, 2018).

Sobre isso, há dois problemas a discutir. Este exercício etimológico generaliza etnomatemática de modo tal que ela se concebe na ausência da matemática como disciplina. Aqui há uma divergência entre as duas concepções. Na perspectiva do presente autor, seria mais conveniente assumir etnomatemática como mais uma etno-x - etno-matemática. Em particular ressalte-se citando um trecho da fala de D’Ambrosio (nota de rodapé 10): O Programa Etnomatemática “É muito mais amplo do que fazer uma etnografia quase do que já existe, mas você quer saber como se chegou a essa situação". Ora, na abordagem das etno-x, se trabalha com o que existe e seja, portanto, passível

\footnotetext{
${ }^{10}$ Em 2 de outubro de 2020 o 'Programa Dá Licença” e o GETUFF, ambos da Universidade Federal Fluminense (UFF), organizaram a 'Mesa de Debate - Etnomatemática, etnociência e decolonialidade” que contou com Ubiratan D'Ambrosio, Marcio D'Olne Campos e a moderação de Maria Cecilia Fantinato. Nela d'Ambrosio repetiu como em 1990, sua mesma concepção de etnomatemática entre os instantes 59:03-1:01:01: “O que eu quero para o Programa Etnomatemática é entender as 'ticas' de 'matema' em diferentes 'etnos'. É muito mais amplo do que fazer uma etnografia quase do que já existe, mas você quer saber como se chegou a essa situação. Esta é a essência do Programa etnomatemática” (59:031:01:01). Disponível em https://www.youtube.com/watch?v=3uGOHb0UXbI\&t=8s [2:07:10]. Acesso em 13 fev. 2021.
} 
da essencial abordagem etnográfica que articula representações individuais e coletivas. Da fala citada, parece que o Programa Etnomatemática dispensa uma etnografia 'do que... já existe' e parece entender que se pesquise no âmbito de uma 'teoria da cognição', ou seja, "saber como se chegou a essa situação [cognitiva]”, não sendo ela passível de uma etnografia. Na perspectiva dambrosiana o prefixo etno- é entendido como associado a cultura e não a grupo social. Assumindo cultura ou grupo social, como este autor, para qualquer dos casos, parece difícil entender que prevaleça uma abordagem cognitiva sobre a etnográfica, tratando-se de cultura. Ressalte-se que num sentido antropológico mais restrito, cultura é entendida como o produto de um grupo social enquanto pensamento é único como processo, segundo Geertz.

Poderíamos conjecturar e perguntar: Como a matemática - ausente da associação da etnomatemática a uma "teoria da cognição" - é "recuperada" associando -tica a -techné e reintroduzindo assim, um termo matemática de novo na etnomatemática.

O segundo aspecto se deve à dificuldade de explicação do significado do sufixo 'tica' que foi levantada por Fabio Lennon Marchon (2016) se perguntando 'Que 'tékhne' é esta da 'tica' da 'etnomatemática'?'

Assim, o pesquisador afirma que tic tem sua raiz etimológica em tékhne que é a mesma de arte. Daí o entendimento de que a Etnomatemática tanto é a arte ou técnica (de fazer algo específico). Porém, não parece totalmente óbvio que 'tic vem sem dúvida de techne' (D’AMBRÓSIO, 1990, p.5). E, mesmo que isto seja um fato inegável (a saber que tica vem de techne e que seu significado é arte ou técnica), ainda assim se pode interrogar filosoficamente o conceito em pauta com intuito de buscar sentidos não evidenciados no texto etnomatemático d'ambrosiano. (MARCHON, 2016, p. 4)

Muitas vezes, a etnomatemática tem sido também referida, embora com certa inconsistência no entender desse autor, como uma metodologia de educação em ciências e matemática.

Apesar disso, as associações com a matemática, enquanto disciplina, são muito frequentes. Paulus Gerdes (1993) a caracteriza basicamente como 'antropologia cultural das matemáticas e do ensino matemático', para em seguida dar-lhe um caráter um pouco mais geral como 'o estudo das práticas e das ideias matemáticas nas suas relações com o conjunto da vida cultural e social'.

Por fim uma questão importante ocorre entre esta conceituação bastante abrangente e generalizadora de Ubiratan D'Ambrósio sobre a etnomatemática (etno + matema + tica) e o que fazer ao 'estar lá' no campo lidando com uma liminaridade de ordem tripla como a da Figura 3. Ou talvez até maior do que a ordem três porque de forma não muito rara, é discutido na academia se a matemática é ou não uma ciência e se ela poderia ser considerada como uma linguagem. 
Tudo isso conduz à pergunta sobre com que recursos o estudante de pós-graduação chega ao campo para uma pesquisa? Pode-se pressupor uma abordagem do 'nativo' - ou do seu grupo social? - por um viés muito amplo e restrito socialmente da 'teoria do conhecimento' ou da 'teoria da cognição'? Difícil!

Isso pareceria deixar em segundo plano o aspecto específico do produto sociocultural da etnia local em benefício da investigação do pensamento que é único como processo (GEERTZ, 1989).

$\mathrm{Ou}$, por outra abordagem, seriam buscados saberes e práticas onde se identificasse, por exemplo, a contagem numérica e propriedades diversas relacionadas às categorias espaço e lugar experimentados no cotidiano? Etno-x?

Estes últimos saberes e práticas como material de investigação etnográfica, seriam então trazidos para o contexto da academia para que analisados interdisciplinarmente no 'estar aqui', fossem abordados - em vista de parecerem se relacionar da aritmética e da geometria predominantemente pela etno-matemática e outras etno-x que se mostrassem necessárias à interdisciplinaridade para vencer a impossibilidade de isomorfismo entre os diferentes contextos de saber.

Terminando, a caracterização da etnomatemática por Bill Barton (2004) parece ter o valor de resolver algumas das dificuldades apresentadas na comparação entre a etnomatemática e das etnomatemática:

Etnomatemática é um programa de pesquisa do modo como grupos culturais entendem, articulam e usam os conceitos e práticas que nós descrevemos como matemáticos, tendo ou não o grupo cultural um conceito de matemática. (p. 53). [grifo do autor]

Assim nos liberamos, de modo mais geral, de caçar nossas disciplinas em grupos sociais estudados, nos limitando apenas a traduzir culturalmente e a trazer para o nosso mundo acadêmico os "conceitos e práticas que nós descrevemos como" ou que se aproximam de alguma de nossas disciplinas da academia.

\section{Considerações Finais}

A partir do que foi discutido faz-se necessário chamar a atenção sobre o perigo quando acadêmicos chegam ao campo entre os 'nativos' e procuram identificar aspectos particulares de suas disciplinas da academia lá onde elas não existem - isomorfismo inexistente!

Uma coleta de elementos constitutivos das disciplinas acadêmicas próprias dos pesquisadores ao irem a campo sugere identificá-los metaforicamente como caçadores-coletores de elementos que valorizem, na academia e sem simetria, suas disciplinas da ciência instituída. 
Com essa forma enganosa de diálogo com o ‘nativo', é exercida e enaltecida a Grande Divisão, aqui severamente criticada e ironizada por Bruno Latour.

\section{Agradecimentos}

Agradeço as preciosas revisões e discussões mantidas com Jéssica Ferreira, Cristina Martins Fargetti e Madalena Mattos Pontes durante a elaboração desse artigo.

\section{REFERÊNCIAS}

BACHELARD, Gaston. A formação do espírito científico. Rio de Janeiro: Contraponto, 1996 [1938].

BAEZ LANDA, Mariano. SUReando al Norte, migraciones mexico-centroamericanas recolonizando el Gabacho. In Revista Interdisciplinar SULEAR, Dossiê SULear (especial), ano 2, n. 2, p. 69-83, 2019.

BARTON, Bill. Dando sentido à etnomatemática: etnomatemática fazendo sentido. In RIBEIRO, José Pedro Machado, DOMITE, Maria do Carmo Santos, FERREIRA, Rogério (orgs.).

Etnomatemática: papel, valor e significado, São Paulo: Zouk, 2004, p. 39-74.

BLOOR, David. Sociologie de la logique ou les limites de l'épistémologie, Paris: Pandore, 1983.

BLOOR, David. Conhecimento e imaginário social, São Paulo: Unesp, 2009.

CAMPOS, Marcio D’Olne. A cosmologia dos Caiapós. Scientific American (Brasil) Edição Especial - Etnoastronomia, 14: 62-71, 2006. Disponível em

$<$ https://www.sulear.com.br/texto11.pdf>. Accesso em 20 jun. 2021.

CAMPOS, Marcio D’Olne; SANZ, Jaqueline. Antropologia Educacional. Vitória (ES): Núcleo de Educação Aberta e à Distância, ne@ad - UFES, 2004. Disponível em

$<$ http://sulear.com.br/beta3/wp-content/uploads/2017/04/CAMPOS-MD-fasciculo-Antropologia-eEAD.pdf>. Acesso em 31 jan. 2020.

CAMPOS, Marcio D’Olne. Etnociência ou etnografia de saberes, técnicas e práticas? In:

AMOROZO, Maria Christina de Mello; MING, Lin Chau; PEREIRA DA SILVA, Sandra Maria (eds.), Métodos de coleta e análise de dados em etnobiologia, etnoecologia e disciplinas correlatas, p. 47-92. Rio Claro: UNESP/CNPq. 2002. 204p. Disponível em http://sulear.com.br/texto02.pdf. Acesso em 31 jan. 2020.

CARDONA, Giorgio Raimondo. La Foresta di Piume: Manuale de Etnoscienza. Roma: Laterza, 1985.

CARDOSO DE OLIVEIRA, Roberto. O trabalho do antropólogo. Brasília: Paralelo15; São Paulo: UNESP, 2000.

COLE, Michael; SCRIBNER, Sylvia, Culture and Thought, New York, Wiley, 1974. 
D'AMBROSIO, Ubiratan. Como foi gerado o nome Etnomatemática ou Alustapasivistykselitys. In: FANTINATO, Maria Cecília e FREITAS, Adriano Vargas (Orgs). Etnomatemática: concepções, dinâmicas e desafios, Jundiaí - SP, 2018.

D'AMBROSIO, Ubiratan. Etnomatemática: arte ou técnica de explicar e conhecer, São Paulo: Ática, 1990.

EVANS-PRITCHARD, Edward. Bruxaria, oráculos e magia entre os Azande. Rio de Janeiro, Zahar, 1978 [1937].

FANTINATO, Maria Cecilia de Castello Branco. A construção de saberes matemáticos entre jovens e adultos do Morro de São Carlos. Revista Brasileira de Educação, Campinas, SP, v. 27, p. 109124, 2004. Disponível em <http://www.educadores.diaadia.pr.gov.br/arquivos/File/2010/artigos_teses/MATEMATICA/artigo _saberes_matematicos.pdf>. Acesso em 19 ago. 2020.

FREIRE, Paulo; CAMPOS, Marcio D'Olne. Leitura da Palavra... Leitura do Mundo. o correio da UNESCO, v. 19, n.2, p. 4-9, fevereiro 1991. Disponível em https://www.sulear.com.br/texto06.pdf. Acesso em 31 jan. 2020.

FREIRE, Paulo. Pedagogia do Oprimido. Rio de Janeiro: Paz e Terra, 1981 [1974].

GEERTZ, Clifford. O Saber Local: Novos ensaios em antropologia interpretativa. Petrópolis, Editora Vozes, 1999

GEERTZ, Clifford. Estar lá, Escrever Aqui. Diálogo, São Paulo, v. 22, n. 3, p. 58-63, 1989.

GERDES, P. L'Ethnomathématique comme nouveau domaine de recherche en Afrique: quelques réflexions et expériences du Mozambique. Maputo/Beira, Mozambique: Institut Supérieur de Pédagogie, 1993.

HAMÚ, Denise (Ed.). A Ciência dos Mebêngôkre. Alternativas contra a destruição (catálogo de exposição). Belém: Museu Paraense Emílio Goeldi, 1987. Disponível em <https://sulear.com.br/beta3/wp-content/uploads/2017/04/CAT-Ciencia-dos-Mebengokre-Goeldi1987.pdf>. Acesso em 31 ago. 2020. Catálogo da exposição.

LANDER, Edgardo (org.), A colonialidade do saber: eurocentrismo e ciências sociais.

Perspectivas latinoamericanas. Colección Sur Sur, CLACSO, Ciudad Autónoma de Buenos Aires, Argentina. 2005. Disponível em <http://biblioteca.clacso.edu.ar/ar/libros/lander/pt/lander.html>.

Acesso em 10 set. 2020.

LEACH, Edmund. Cultura e Comunicação - A Lógica pela Qual os Símbolos Estão Ligados Uma Introdução ao Uso da Análise Estruturalista em Antropologia Social. Rio de Janeiro, Zahar Editores, 1978 [1976].

LATOUR, Bruno; WOOLGAR, Steve. A Vida de Laboratório: A produção dos fatos científicos, Rio de Janeiro: Relume Dumará, 1997[1979].

LATOUR, Bruno. "Comment Redistribuer le Gran Partage ? Revue de Synthèse, CIV (110): 203235,1983 . 
LATOUR, Bruno. Como redividir a Grande Divisão, MOSAICO - Revista de Ciências Sociais (Sala de Aula), Ano 2, Número 2, v. 1, 1983a.

MARCHON, F. L. Que "tékhne" é esta da "tica" da "etnomatemática"? In: XII Encontro Nacional de Educação Matemática (XII SBEM), 2016, São Paulo. Anais... São Paulo: SBEM, 2016.

MURDOCH, Jonathan; CLARK, Judy. Sustainable Knowledge. Geoforum, Oxford, v. 25, n. 2, p. 115-132, 1994.

POSEY, Darrell Addison. Introdução: Etnobiologia, teoria e prática. In: RIBEIRO, D. Suma Etnológica Brasileira. Petrópolis: Vozes; FINEP, 1986, cap. 1, p. 15-25.

VALLADARES, Licia. Os dez mandamentos da observação participante. Rev. Bras. Ci. Soc., São Paulo, v. 22, n. 63, p. 153-155, fev. 2007. Disponível em

$<$ http://www.scielo.br/scielo.php?script=sci_arttext\&pid=S0102-

69092007000100012\&lng=en\&nrm=iso>. Acesso em 19 ago. 2020. 